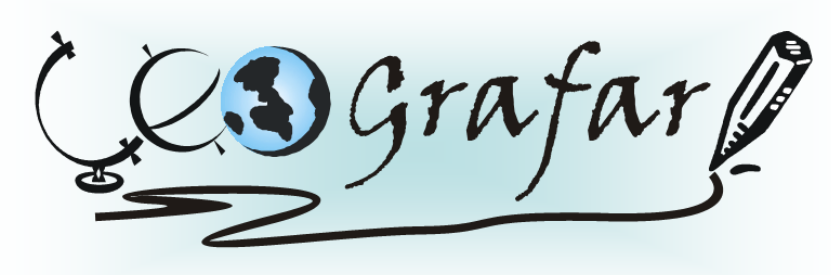

Revista Eletrônica do Programa de Pós-Graduação em Geografia - UFPR

\title{
PORTO VELHO: A PRODUÇÃO DO ESPAÇO URBANO DE RONDÔNIA (1980/2010)
}

\author{
CLÁUDIA PINHEIRO NASCIMENTO ${ }^{1}$ \\ CARLOS SANTOS ${ }^{2}$ \\ MAURÍCIO SILVA ${ }^{3}$
}

\begin{abstract}
RESUMO
O presente artigo tem como objetivo discutir o processo de formação sócio espacial da cidade de Porto Velho, do período de 1980 a 2010, a partir da sua inserção na realidade urbana de Rondônia. Utilizou-se como base teórica para a discussão diversos trabalhos acerca da temática, assim como técnicas de sensoriamento remoto e geoprocessamento em suporte das análises da expansão da mancha urbana da cidade. A discussão acompanhará a formação sócio-espacial da área em questão, como modo de interpretação da produção urbana, levando-se em consideração as especificidades sociais, políticas, econômicas e culturais que marcaram Rondônia e sua Capital ao longo do processo histórico recente da região.
\end{abstract}

Palavras-chave: Urbanização, Amazônia, Rondônia, Porto Velho.

\footnotetext{
${ }^{1}$ Mestre em Geografia pela Universidade Federal de Rondônia. Colaboradora do Instituto Nacional de Pesquisas Espaciais, INPE/Amazônia. E-mail: nascimento.cp@gmail.com.

${ }^{2}$ Professor Doutor do Departamento de Geografia da Universidade Federal de Rondônia. E-mail: herodoto@unir.br

${ }^{3}$ Pesquisador do Instituto Nacional de Pesquisas Espaciais - INPE/Amazônia. E-mail: mauricio.silva@cra.inpe.br
} 


\section{PORTO VELHO: THE PRODUCTION OF THE URBAN SPACE IN RONDÔNIA}

\section{(1980/2010)}

\section{ABSTRACT}

This paper aims to discuss the process of socio-spatial formation to the city of Porto Velho, the period between 1980 and 2010, from its participation into the urban reality of Rondônia. As a theoretical basis for the discussion, several works on the theme was used, as well as remote sensing and GIS analysis to support the expansion of the urban growth of the city. The analysis will monitor the socio-spatial formation of the area in question as a way of interpretation of urban spatial construction, taking into account the specific social, political, economic and cultural capital that marked Rondônia in the process the region's recent history.

Keywords: Urbanization, Amazon, Rondônia and Porto Velho.

\section{INTRODUÇÃO}

A urbanização de Rondônia, assim como a que ocorreu em outras regiões da Amazônia Ocidental, aconteceu, sobretudo, em função dos desdobramentos dos processos de integração da Amazônia. Tal processo, ao induzir o surgimento de núcleos urbanos, como centros de comando político/administrativo/econômico, produziu um espaço de expansão da recente modernização brasileira que se contrapõe e subverte o antigo modo tradicional/extrativista dominante na região.

Rondônia, portanto, constituiu-se numa nova espacialidade agrícola, trocando sua cobertura de floresta por lavouras e, principalmente, por pastos, a exemplo das áreas de cerrado do Centro-Oeste, que cederam sua ecologia para a cultura da soja e da pecuária. Rondônia agora ensaia vigorosamente, impulsionada por projetos que atendem à necessidade energética do país, uma nova onda urbanizatória, Porto Velho é a vitrine dessa nova Rondônia.

Sendo assim, a análise do processo de ocupação e urbanização de Porto Velho precisa levar em consideração os desdobramentos do crescimento econômico brasileiro e seus reflexos na Amazônia.

Dentro desta perspectiva, fica difícil separar o processo de urbanização de Rondônia do ocorrido em Porto Velho, uma vez que as políticas implantadas para a incorporação e ocupação de Rondônia impactaram diretamente a formação social e espacial de Porto Velho, sua capital político-administrativa, a partir da qual a 
urbanização se difundiu para o restante do estado. E de tal modo, que se pode falar de que Porto Velho é que induziu a urbanização de Rondônia.

Este artigo pretende analisar os mecanismos responsáveis pelo processo de crescimento urbano de Porto Velho entre os anos de 1980 e 2010, como reflexo da dinâmica de ocupação e colonização de Rondônia.

A análise acompanhará a formação sócio-espacial da área em questão, como modo de interpretação da produção urbana, levando-se em consideração as especificidades sociais, políticas, econômicas e culturais que marcaram Rondônia e sua Capital ao longo do processo histórico recente da região. (NASCIMENTO, 2009)

Como suporte das análises foram utilizadas técnicas de geoprocessamento e sensoriamento remoto, que, a partir da construção de um sistema de informação geográfica, permitiu identificar a evolução espaço temporal utilizando imagens de satélite. Através destas foi possível analisar o avanço da mancha urbana de Porto Velho e associá-las à análise do crescimento da população, instrumento que viabilizará a compreensão da construção do cenário urbano de Porto Velho, do ano de 1980 ao ano de 2010.

\section{LOCALIZAÇÃO DA ÁREA DE ESTUDO}

O estado de Rondônia está situado na porção Sul da região Norte do Brasil, inserido na Amazônia Ocidental, possui 237.576,167 Km² de área territorial segundo IBGE, ocupados por uma população estimada no ano de 2010 de 1.562 .409 habitantes. O Estado está subdividido em 52 municípios, tendo como maior cidade, sua capital Porto Velho, com 428.527 habitantes. Destacam-se ainda as cidades de Ji-paraná (116.610 hab.), Cacoal (78.574 hab.) e Vilhena (76.202 hab.) como cidades de maior porte no Estado. (http://www.ibge.gov.br/cidadesat)

Está compreendido entre as latitudes de $7^{\circ} 58^{\prime} \mathrm{S}$ e $13^{\circ} 41^{\prime} \mathrm{S}$ e longitudes $59^{\circ}$ 46' W e 66 48' W. Possui limites com os estados do Amazonas (N), Mato Grosso (L), e Acre (W) e com a Bolívia (S e W) por cerca de 1.000 quilômetros. O clima predominante é o tropical úmido apresentando uma estação seca bem definida entre junho e agosto e precipitação média em torno de $2.500 \mathrm{~mm} / \mathrm{ano}$. (RADAMBRASIL, 1978), conforme localização na figura 1. 
Figura 1 - Localização do estado de Rondônia
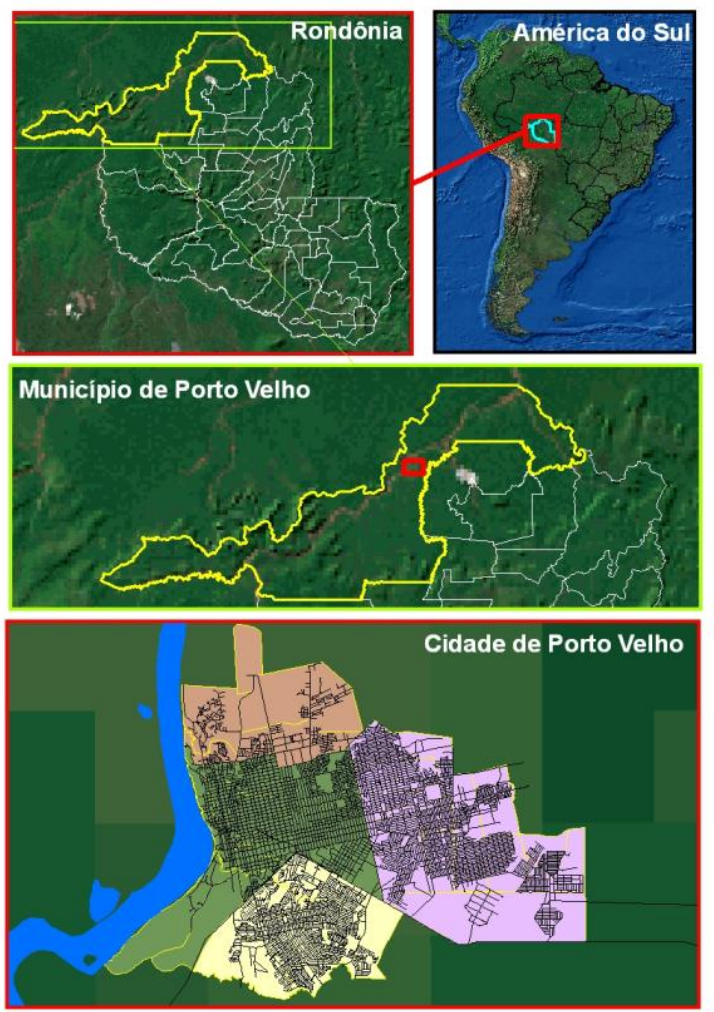

Fonte: O AUTOR. Mapa elaborado com software ArcGis 9.0 (ESRI, 2001)

\section{TRAÇOS DA URBANIZAÇÃO DE RONDÔNIA}

A rede urbana de Rondônia é composta, basicamente, pelos núcleos demográficos ao longo da BR- 364, destacando-se, além da capital Porto Velho, as cidades do centro-sul do estado, em função de certo dinamismo agroindustrial. É o caso de Ji-Paraná, no centro do estado, e Vilhena no extremo sul, que disputam a liderança do interior, com clara vantagem para a primeira. Seguem-se Ariquemes, Cacoal, Jaru, Ouro Preto d'Oeste, Rolim de Moura, Pimenta Bueno. Essa estrutura urbana, autêntica espinha dorsal, comanda toda a malha de núcleos urbanos do estado a partir de Porto Velho. É resultante das três "gerações urbanas" detectadas por Coy (1988). Havia, de início, apenas os núcleos tradicionais ao norte e noroeste na época da construção da estrada de ferro Madeira-Mamoré. Em seguida, surgiram os núcleos pioneiros ao longo da BR-364, em torno dos antigos postos telegráficos (Ji-Paraná, Pimenta Bueno e Vilhena). Por último, as cidades que surgem nas novas 
áreas de assentamento ao longo dos eixos secundários da expansão colonizatória (Rolim de Moura).

As dez cidades mais populosas do estado em dois momentos, 2000 e 2010, são:

Quadro 1A - Cidades mais populosas de Rondônia - 2000

\begin{tabular}{|c|c|c|c|}
\hline GERAÇÃO URBANA & CIDADES & POP. URB. & \% RURAL MUNC. \\
PRIMEIRA & PORTO VELHO & 273496 & 18,26 \\
\hline PRIMEIRA & GUAJARÁ-MIRIM & 33004 & 13,17 \\
\hline SEGUNDA & JI-PARANÁ & 90873 & 14,78 \\
\hline SEGUNDA & ARIQUEMES & 54875 & 26,17 \\
\hline SEGUNDA & CACOAL & 51379 & 30,15 \\
\hline SEGUNDA & VILHENA & 50504 & 5,59 \\
\hline SEGUNDA & JARU & 29229 & 44,65 \\
\hline SEGUNDA & PIMENTA BUENO & 26417 & 16,78 \\
\hline SEGUNDA & OURO PRETO D' & 26519 & 35,10 \\
\hline TERCEIRA & OESTE & 34322 & 27,41 \\
\hline TOTAL & ROLIM DE MOURA & 670618 & - \\
\hline
\end{tabular}

Fonte: IBGE 2000

Quadro 1B - Cidades mais populosas de Rondônia - 2010

\begin{tabular}{|c|c|c|c|}
\hline GERAÇÃO URBANA & CIDADES & POP. URB. & \% RURAL MUNC. \\
PRIMEIRA & PORTO VELHO & 391.014 & 9,00 \\
\hline PRIMEIRA & GUAJARÁ-MIRIM & 35.197 & 18,00 \\
\hline SEGUNDA & JI-PARANÁ & 104.841 & 11,20 \\
\hline SEGUNDA & ARIQUEMES & 69.606 & 29,80 \\
\hline SEGUNDA & CACOAL & 61.931 & 26,91 \\
\hline SEGUNDA & VILHENA & 72.212 & 5,50 \\
\hline SEGUNDA & JARU & 35.141 & 48,09 \\
\hline SEGUNDA & PIMENTA BUENO & 29.358 & 14,97 \\
SEGUNDA & OURO PRETO D' & 28.208 & 34,50 \\
\hline TERCEIRA & OESTE & 41.454 & 22,23 \\
\hline TOTAL & ROLIM DE MOURA & 868.962 & - \\
\hline
\end{tabular}

Fonte: IBGE, 2010.

A urbanização de Rondônia, em que $73,2 \%$ da população reside em cidades e $86,5 \%$ nas dez maiores cidades (dados atualizados), acompanha a tendência geral de urbanização da fronteira de povoamento amazônica (MACHADO, 1979, 1990). Embora muitos núcleos pioneiros urbanos apresentem significativa flutuação populacional (não captada pelos dados censitários) devido à instabilidade dos fluxos migratórios, a estrutura urbana constitui a base-padrão do povoamento do território. 
Dois aspectos do quadro $1 \mathrm{~A}$ podem ser destacados. Primeiro, Rolim de Moura é a única cidade da "terceira geração", situada entre as dez maiores aglomerações, indicando sua atual situação de "boca do sertão" para a corrente de povoamento que se dirige à "fronteira do Guaporé". O segundo aspecto é a grande variação da população rural nos municípios que abrigam as maiores cidades, o que indica a diversidade evolutiva dos antigos projetos de colonização agrícola. Acrescente-se que mais da metade da população rural do estado (2000/2010) não se encontra ao longo da BR-364, e sim nas novas áreas de assentamento ao longo dos eixos secundários. A primeira metade da década de 1990, portanto, caracterizase pela abertura de frentes no interior em vez de adensamento da ocupação agrícola ao longo do grande eixo rodoviário.

A condição urbana se dá em função da inserção do povoamento, no que Pumain denomina de sistema técnico-territorial, "um aparato tecnológico capaz de controlar e regular todos os aspectos da cotidianidade da vida diária por meio de formas institucionais" (1995, p.19). A autora analisa fatores como comunicação, troca e interdependência, algo comum e necessário entre as cidades, a ponto de constituírem propriedades que definem geograficamente a cidade, dentro de uma unidade territorial. A dinâmica do sistema urbano, ou seja, sua evolução é autoorganizativa e afeta todos os componentes (1997, p.124). Para Denise Pumain (1995, p.127) "a rede urbana ou sistema de cidades pode ser definido simplesmente como um subconjunto de um sistema de povoamento". Esse sistema é balizado por dois modos de produção do espaço geográfico, duas dimensões de velocidade de mudança: um histórico, ligado à evolução dos processos de exploração ecológica, isto é, da produção do urbano propriamente dito; e outro tecnológico, em função da conectividade às redes informacionais, responsáveis pela contração do espaçotempo (PUMAIN, 1997, p.132).

Enfim, à guisa de ilustração, o gráfico a seguir exibe a dinâmica urbanizatória, em termos comparativos, nas escalas estadual, regional e nacional: 


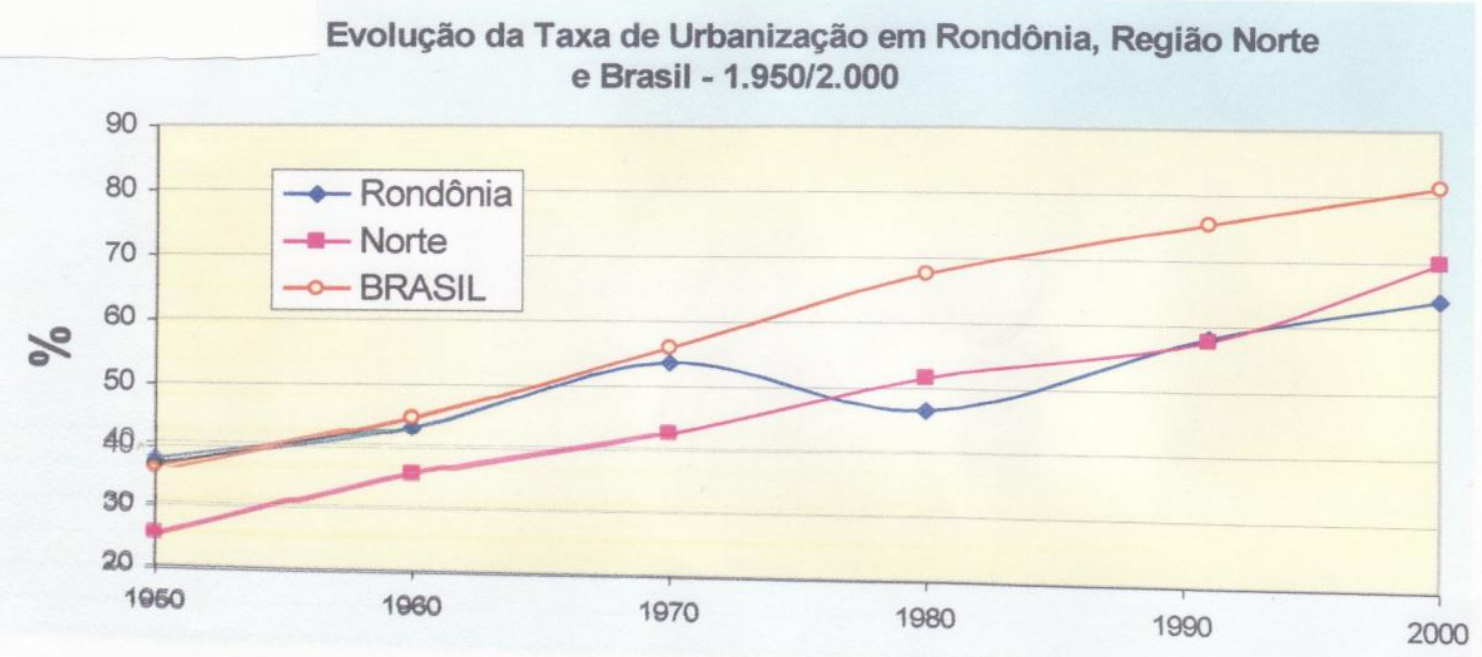

Fonte: Gráfico extraido de relatório de Emanuel Meireles - Sem data

Como os projetos de colonização agrícola constituíram-se no principal atrator da ocupação do estado, seria de se esperar que a comercialização dos produtos agrícolas e a prestação de serviços para a população rural fossem as principais funções das pequenas cidades que cresceram no último decênio. Contudo, embora essas funções sejam importantes, o quadro 2 mostra que a urbanização também está relacionada ao crescimento da atividade industrial, tanto no domínio da economia formal como da informal.

Quadro 2 - Rondônia: capacidade industrial - 1987 / 1993 / 1995 / 1997/ 2002

\begin{tabular}{|c|c|c|c|c|c|}
\hline CIDADES COM MAIS DE 100 INDÚSTRIAS & 1987 & 1993 & 1995 & 1997 & 2002 \\
\hline PORTO VELHO & 340 & $1266+$ & $783-$ & $599-$ & $822+$ \\
\hline ARIQUEMES & 306 & $319+$ & $375+$ & $205-$ & $258+$ \\
\hline JI-PARANÁ & 223 & $250+$ & $409+$ & $262-$ & $365+$ \\
\hline OURO PRETO D'OESTE & 188 & $133-$ & $148+$ & $83-$ & $98+$ \\
\hline CACOAL & 162 & $118-$ & $182+$ & $129-$ & $207+$ \\
\hline VILHENA & 159 & $169+$ & $225+$ & $157-$ & $216+$ \\
\hline PIMENTA BUENO & 151 & $112-$ & $161+$ & $115-$ & $153+$ \\
ROLIM DE MOURA & 149 & $123-$ & $197+$ & $138-$ & $154+$ \\
\hline JARU & 134 & $108-$ & $226+$ & $116-$ & $152+$ \\
\hline TOTAL & 1812 & 2598 & 2706 & 1804 & 2425 \\
\hline
\end{tabular}

Fonte: FIERO, 2002. 
Entre 1950/2010, a população de Rondônia evoluiu do seguinte modo:

Quadro 3 - Rondônia: evolução da população - 1950-2010

\begin{tabular}{|c|c|c|c|c|}
\hline ANO & \multicolumn{3}{|c|}{ POPULAÇÃO } & TOTAL \\
\hline 1950 & URBANA & RURAL & $\%$ URB/RUR & \\
\hline 1960 & 13816 & 23119 & $37,4 / 62,6$ & 36935 \\
\hline 1970 & 30186 & 39606 & $43,2 / 56,8$ & 69792 \\
\hline 1980 & 59564 & 51500 & $53,6 / 46,4$ & 111064 \\
\hline 1991 & 228168 & 262857 & $46,4 / 53,6$ & 491025 \\
\hline 1996 & 768172 & 472702 & $58,2 / 41,8$ & 1130874 \\
\hline 2000 & 883048 & 468143 & $61,9 / 38,0$ & 1231007 \\
\hline 2010 & 1.142 .648 & 494744 & $62,7 / 35,9$ & 1377792 \\
\hline
\end{tabular}

Fonte: IBGE, 2010.

Não há dúvida de que o processo de ocupação, após 1980, precisamente quando se acentua a imigração para a região, caracteriza-se pela crescente urbanização da população. Mesmo assim, mais de dois terços da população residia em áreas rurais (38\%) em 1996. Considerando-se, ademais, que uma parcela significativa das famílias de pequenos proprietários rurais reside nas cidades e vilas, é possível que um contingente maior do que aquele, mostrado no quadro 3 acima, dependa das atividades rurais e agrícolas, embora residindo nas cidades.

Assim, a atividade industrial em Rondônia ainda é bastante incipiente. Os ciclos de extrativismo minero-vegetal por que passou a economia do estado não implicou o surgimento de um setor de transformação de produtos primários. Entretanto, o processo de colonização estimulou a construção civil, de vez que a migração provocou a demanda por obras públicas e o crescimento do mercado habitacional, mormente com a chegada de servidores públicos para compor os quadros institucionais. Afora o segmento da construção civil, as atividades do setor secundário abrangem ainda o segmento madeireiro, e seu desdobramento na indústria moveleira, e a mineração, principalmente após a criação da Província Estanífera de Rondônia. Acompanhando esse processo, vem se desenvolvendo a indústria de alimentos, setor que vem ganhando relevo a ponto de ser atualmente, segundo a FIERO (1997), o primeiro colocado em quantitativo de empresas. 


\section{O PROCESSO DE URBANIZAÇÃO DE PORTO VELHO}

\subsection{A PRODUÇÃO ESPACIAL URBANA DE PORTO VELHO DE 1980 A 2010}

A produção espacial urbana da cidade de Porto Velho, a partir da década de 1980 ao ano de 2010, incorpora, sobretudo, as políticas de correção implantadas com o intuito de reorganização do espaço rondoniano, em função das políticas aplicadas anteriormente, principalmente os projetos de colonização, o ciclo do ouro no rio Madeira e as novas políticas de incorporação da região, como o Plano de Aceleração do Crescimento do Governo Federal (PAC), que inclui a construção de duas usinas hidrelétricas (UHE Santo Antônio e UHE Jirau) no município de Porto Velho.

A comparação dos dados referentes ao crescimento da população de Porto Velho face a evolução da mancha urbana da cidade, juntamente com a análise dos elementos sociais, políticos e econômicos, permite construir uma visão mais próxima da realidade do cenário urbano, entre os anos de 1980 e 2010.

Os dados referentes aos censos do IBGE dos anos de 1980 a 2010, com o predomínio da população urbana sobre a rural (conforme quadro 3 e gráfico 1), vêm reafirmar a condição de centro regional que a cidade de Porto Velho assumiu frente às demais cidades do estado, assim como seu papel de centro de serviços, com influência no Acre e no sudoeste do estado Amazonas.

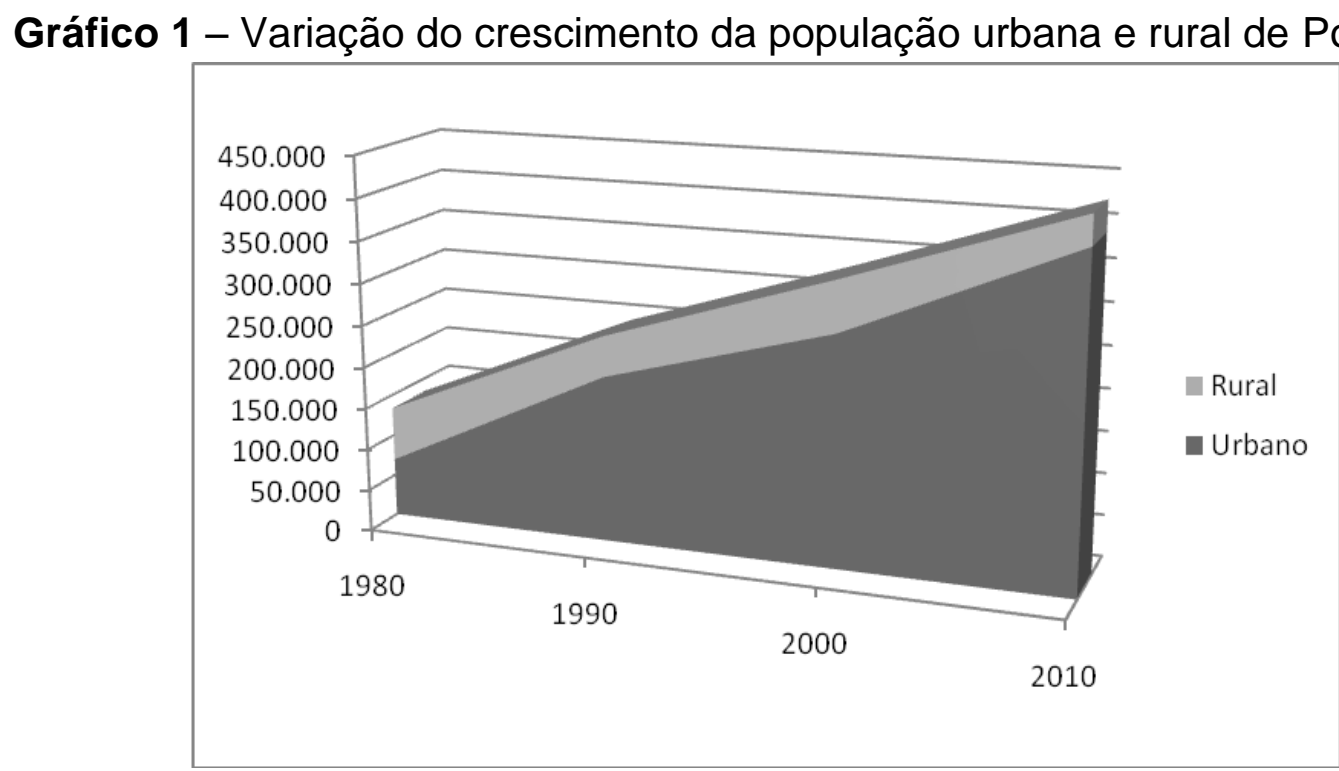

Fonte: Dados do IBGE 
O aumento da população urbana da cidade em detrimento da população rural correlaciona-se, de forma direta, com os ciclos econômicos e as intervenções do estado nacional na região, seja através da implantação de planos econômicos, planos ambientais ou construção de infraestrutura.

O aumento da população urbana na década de 1980 está associado ao reflexo do relativo fracasso dos projetos de colonização implantados no estado durante a década de 1970, que pela falta de gestão adequada do governo federal, não permitiu a fixação da população na terra, o que levou a uma busca na cidade, principalmente Porto Velho, por novas opções de ocupação e melhores condições de vida.

A descoberta de ouro no rio Madeira também foi um fator de grande contribuição para o aumento da população urbana, que, além de verem na exploração do ouro a oportunidade de enriquecer, tinham a chance de deixar as áreas rurais onde se localizavam os projetos de colonização, por estes não mais oferecerem a manutenção mínima de substência de suas famílias, conforme gráfico I.

A implementação em maio de 1981, pelo Banco Mundial, do POLONOROESTE (Programa de Desenvolvimento Integrado do Noroeste do Brasil), que visava a promoção do desenvolvimento sócio-econômico e o ordenamento da ocupação humana em Rondônia e Mato Grosso (MAHAR, 1983), além do financiamento da construção e pavimentação da rodovia entre Cuiabá e Porto Velho (BR-364), que, ao facilitar a migração, contribuiu para o aumento da população na região.

Porém, os reflexos deste grande surto migratório que se estabelece na região em função da exploração do ouro do Madeira somente vão ser detectados, com mais clareza, nos dados referentes ao ano de 1990, quando o ciclo de exploração alcança seu ápice, entrando em declínio em meados da década de 1990.

Os dados referentes ao crescimento da população total no ano de 1990, com um índice de $85 \%$ de crescimento total e de $186 \%$ de crescimento da população urbana, confirmam o reflexo do processo que se estabeleceu em Porto Velho na década de 1980, com a exploração do ouro, nos dados de 1990, conforme quadro 4 e gráfico 2. 
Quadro 4 - Porcentagem de crescimento da população rural e urbana de Porto Velho

\begin{tabular}{|l|r|r|r|}
\cline { 2 - 4 } \multicolumn{1}{c|}{} & \multicolumn{1}{c|}{1990} & \multicolumn{1}{c|}{2000} & \multicolumn{1}{c|}{2010} \\
\hline$\%$ CRESC. POP TOTAL & $85 \%$ & $35 \%$ & $27 \%$ \\
\hline$\%$ CRESC. POP URB & $186 \%$ & $38 \%$ & $43 \%$ \\
\hline$\%$ CRESC. POP RURAL & $-25 \%$ & $26 \%$ & $-42 \%$ \\
\hline
\end{tabular}

Fonte: Dados do IBGE

Gráfico 2 - Crescimento da população rural e urbana

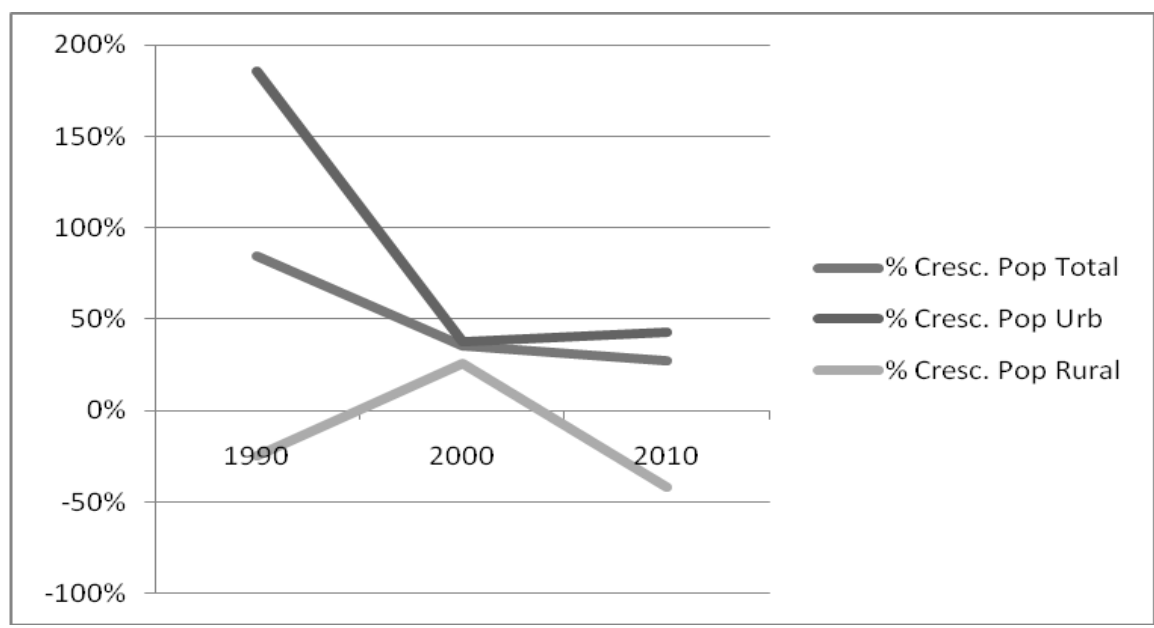

Fonte: Dados do IBGE.

A estagnação aparente entre o ano de 1990 e o ano 2000, vem reafirmar a associação do crescimento da cidade aos grandes projetos e ciclos econômicos, pois esta década foi marcada pela inaplicabilidade de planos econômicos, pela diminuição dos incentivos às obras de infraestrutura, além da ausência da descoberta de minérios ou de produtos primários voltados à exportação.

A década de 1990 foi marcada também pela implantação de políticas ambientais que visavam principalmente a amenizar os estragos referentes ao uso irracional dos recursos naturais durante os projetos de colonização e nos períodos de exploração do ouro e da cassiterita, através do PLANAFLORO (Plano Agropecuário e Florestal de Rondônia).

Segundo Santos (2001, p.112), trata-se de uma política de reordenamento ambiental baseado na identificação de áreas homogêneas ecologicamente, tipificadas como zonas capazes de permitir um claro planejamento para o seu uso. 
Este planejamento teve como foco a produção de espacialidades marcadas por um viés determinista, no sentido de que o uso dessas áreas estaria determinado pelas condições naturais das mesmas e não por uma valorização científica ou social.

O crescimento verificado durante os anos de 2000 a 2010, demonstra a dinâmica que as obras do Plano de Aceleração do Crescimento vão impor à região, a partir da implementação de obras de infraestrutura e dos grandes projetos hidrelétricos de Santo Antônio e Jirau.

A divulgação da implantação de grandes obras de infraestrutura que se associam diretamente à idéia de desenvolvimento traz uma nova dinâmica à cidade de Porto Velho, a partir da oportunidade de novos negócios e de trabalho, associado aos fluxos migratórios sempre presentes na história da formação sócio espacial da cidade.

\subsection{ELEMENTOS CONSTITUINTES DO ESPAÇO URBANO}

A década de 1980 é decisiva para a economia da cidade de Porto Velho, em virtude da exploração do ouro no Rio Madeira, que incorporará à região uma nova dinâmica migratória e uma gama de serviços que surgem como forma de dar suporte às novas demandas que surgem.

As notícias de ouro, no rio Madeira, atraíram uma grande quantidade de garimpeiros que vinham para a região com o intuito de enriquecer rapidamente. Em 1980 começaram a chegar as primeiras balsas vindas do Pará, a exploração em terra firme também aconteceu, contudo, sua participação não adquiriu a importância como a dos garimpos fluviais (TEIXEIRA e FONSECA, 2002).

Uma gama de serviços e atividades surgiu com a implantação dos garimpos, sejam eles manuais ou através dragas e balsas. Estas atividades não compreendiam aquelas envolvidas diretamente na extração, mas envolviam atividades que incluíam as relacionadas ao comércio, serviços, lazer, imobiliárias entre outras.

A proximidade dos garimpos da cidade de Porto Velho associada à estruturação que a mesma já possuía em razão de ter se constituído como centro regional, desde a implantação dos demais núcleos urbanos do estado, fez com que ocorresse na região grandes transformações. 
Duas grandes transformações se destacam neste momento, a primeira associada aos fluxos migratórios, que faz com que a população tenha um aumento significativo, e a outra associada à expansão do perímetro urbano da cidade.

A nova leva de pessoas que se deslocam dos projetos de assentamento nas áreas rurais associada às pessoas que vêm de outras áreas do país em busca de ouro, ou de novas oportunidades de trabalho e de vida, faz com que a malha urbana da cidade de Porto Velho sofra uma expansão considerável, pois passa a comportar este grande fluxo migratório.

A grande disponibilidade de terras devolutas urbanas longe do centro da cidade pertencentes, na sua grande maioria, à União, provocou o fenômeno muito conhecido na região das invasões, em que as famílias se deslocavam para as áreas desocupadas, limpavam os terrenos, demarcavam, construíam pequenos barracos e tomavam a posse da terra. Fenômeno que teve incentivo de alguns políticos visando votos, e também do setor imobiliário que mantém várias áreas desocupadas próximas à área central para especulação. Por conta disso, Porto Velho exibe uma malha urbana bastante espalhada não condizente com seu tamanho demográfico.

Não havia serviços básicos como água encanada, iluminação elétrica e tratamento de esgoto, muitas vezes nem o acesso ao local era viável, porém com o passar do tempo estes serviços iam sendo implantados, valorizando as áreas próximas, deixadas sem ocupação como forma de especulação imobiliária. Estas áreas, com o passar dos anos, vieram a ser os bairros que compõem o perímetro urbano da cidade de Porto Velho.

Este processo desenfreado de ocupação trouxe como conseqüência à cidade de Porto Velho índices muito baixos em relação aos serviços básicos, deixando a capital de Rondônia muito abaixo da média em relação a outras capitais.

Dos 26.023 domicílios pesquisados na década de 1980, 6.533, ou seja, $25 \%$ possuíam abastecimento de água pela rede geral com canalização interna, 1.906 residências, ou seja, 7,34\% possuíam poços ou nascentes como forma de abastecimento de água. Destes 3.032, ou seja, $11,65 \%$ são abastecidos pela rede geral, mas não possuem canalização interna, e 10.849 residências, ou seja, 41,69\% possuem poços ou nascentes sem canalização interna (Dados IBGE, 1980). 
Mesmo os dados de Porto Velho se destacando frente aos demais municípios, os números apresentam-se muito baixos para uma realidade de uma capital de estado.

A elevação do Território Federal de Rondônia à categoria de Estado vai impor um novo ritmo à cidade de Porto Velho, que continua como capital do estado, mas vai ter sua dinâmica transformada em razão das condições necessárias para a implantação do Estado. Isto inclui as construções que irão comportar a nova leva de políticos e funcionários públicos necessários para o funcionamento do estado.

O caráter das atividades desenvolvidas demonstra este período de transformação pelo qual a cidade de Porto Velho passa atualmente. Segundo os dados estatísticos do IBGE da década de 1980, as atividades agropecuárias, de extração silvícola e de pesca tiveram uma queda significativa em relação a números, apresentando um aumento nas áreas rurais onde os projetos de colonização foram implantados ou estavam em vias de implantação.

$\mathrm{Na}$ década de 1980 vivencia-se, também uma grande quantidade de programas que se instituíam neste período como forma de tentar amenizar os problemas sociais e ambientais que se estruturavam no Estado em função das políticas de colonização implantadas.

Foi no início da década de 1980 que os problemas da ocupação amazônica passaram a aparecer no cenário nacional. A ideologia do vazio demográfico havia dado abertura para a noção de propriedade privada, desconhecida dos povos da floresta (índios e seringueiros), e a descoberta da fragilidade da terra, agora nua, sem cobertura florestal, demonstrando sua incompatibilidade frente ao trabalho nela realizado. A queimada e o desmatamento fazem parte das etapas da técnica tradicional de cultivar a terra.

Em dezembro de 1980, o Banco Mundial anunciou a decisão de financiar a reconstrução e pavimentação da rodovia entre Cuiabá e Porto Velho, como parte de um programa para promover o desenvolvimento sócio-econômico e "ordenamento" da ocupação humana em Rondônia e Mato Grosso (MAHAR, 1983).

Em maio de 1981, o Governo Brasileiro criou oficialmente o Programa de Desenvolvimento Integrado do Noroeste do Brasil (POLONOROESTE) através do Decreto Presidencial nº 86.029/81. A área de abrangência do POLONOROESTE incluiria o Território Federal de Rondônia e quatorze municípios no centro-oeste de 
Mato Grosso, totalizando 410.000 quilômetros quadrados (ou quase $5 \%$ do território nacional).

O objetivo do Polonoroeste era corrigir os problemas sócio-ambientais gerados pela colonização na década de 1970, e incluía medidas como a pavimentação da BR 364 a partir de Cuiabá até Porto Velho, a construção de estradas vicinais, assim como a preservação de comunidades indígenas e extrativistas.

Devido à fragilidade do desempenho do Polonoroeste, em 1984 o programa sofre uma reformulação, com o intuito de arrumar as inconsistências entre o que havia sido estabelecido no plano e o que foi efetivamente implantado.

Neste momento, a cidade de Porto Velho apresenta uma área central mais estruturada comercial e economicamente e nas questões relacionadas à infraestrutura conforme figura 2, mas a sua expansão rumo às áreas mais afastadas no núcleo central começa a se intensificar a partir da década de 1980.

Figura 2 - Vista parcial de Porto Velho - década de 1980

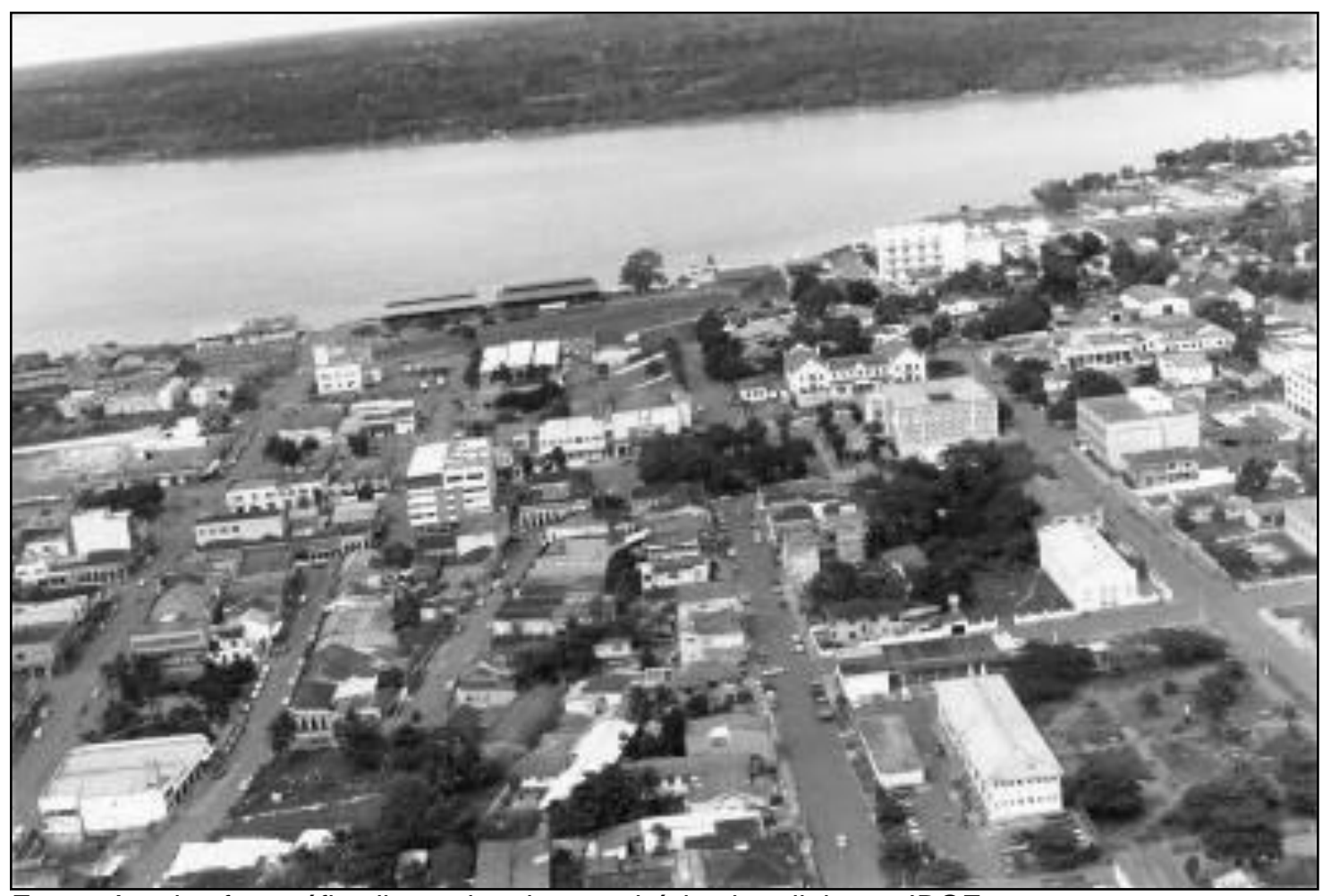

Fonte: Arquivo fotográfico ilustrativo dos municípios brasileiros - IBGE. 
Os dados da década de 1990 vão mostrar as conseqüências dos processos que se estabeleceram em Porto Velho durante a década de 1980 e como a dinâmica populacional passa a se comportar.

As condições sociais da cidade de Porto Velho não apresentam grandes mudanças, das 63.323 residências pesquisadas, somente 24.030 possuem rede geral de água com canalização interna, 12.080 possuem poços ou nascentes e 503 apresentam outras formas de abastecimento. Das residências que não apresentam canalização interna, 7.025 possuem rede geral, 16.724 poços ou nascentes e 2.961 possuem outra forma de abastecimento (Dados IBGE, 1990).

As condições sanitárias apresentam-se ainda piores em relação aos números: das 63.323 residências, 50.309 possuem alguma forma de escoamento sanitária, mas de forma precária, 585 apresentam rede geral de escoamento, 5.347 fossas sépticas ligadas à rede pluvial, 25.496 possuem fossa séptica sem escoamento, 15.583 fossas rudimentares. 1.542 utilizam valas como forma de escoamento e 676 utilizam outras formas de escoamento de esgoto (Dados IBGE, 1990).

O Estado de Rondônia vivencia na década de 1990 a implantação de uma política de ordenamento ambiental o PLANAFLORO $^{4}$ (Plano Agropecuário e Florestal de Rondônia).

O Planafloro continha uma série de componentes que objetivavam mitigar os problemas causados por seu antecessor e incluía uma série de objetivos relacionados à proteção ambiental. Um pré-requisito para a aprovação do empréstimo por parte do Banco Mundial foi a criação do Zoneamento Agroecológico de Rondônia, que foi aprovado pela Assembléia Legislativa em junho de 1988. Além de dividir o estado em seis zonas diferentes, o Zoneamento foi desenvolvido com o objetivo de assegurar uma utilização controlada dos recursos naturais existentes em Rondônia. (PEDLOWSKI et al, 1999, p. 56)

Segundo Santos (2001, p.112), trata-se de uma política de ordenamento ambiental baseado na identificação de áreas homogêneas ecologicamente, típicas como zonas capazes de permitir um claro planejamento para o seu uso. Este planejamento teve como foco a produção de espacialidades marcadas por um viés

\footnotetext{
${ }^{4}$ A implantação do programa, em linhas gerais, visava os seguintes objetivos: a) reformulação das agências locais; b) conservar a biodiversidade rondoniana; c) proteção aos limites das áreas de reserva indígena; d) desenvolvimento, de modo integrado, da colonização agrícola sustentada e dos sistemas de manejo florestal; e) prioritarização de investimentos em infra-estrutura e serviços para melhorar os programas em áreas já ocupadas; e f) adequação da rede institucional local. (SANTOS, 2001:113)
} 
determinista, no sentido de que o uso dessas áreas estaria determinado pelas condições naturais das mesmas e não por uma valorização científica ou social das mesmas.

A implantação efetiva do PLANAFLORO representou mudanças efetivas nas relações entre o Poder Público, sociedade e meio ambiente. Nesse sentido, a história tem demonstrado o uso predatório dos recursos naturais e uma grande quantidade de conflitos sociais. O PLANAFLORO representaria a adoção de práticas de novos valores e padrões de comportamento que abrangeria o Estado e a sociedade civil, inclusive através de associações não governamentais e sindicatos, em que os recursos naturais devem ser utilizados dentro da perspectiva da sustentabilidade, além da redução das desigualdades sociais e da valorização das diversidades culturais (SANTOS, 2001).

Um dos pontos que merecem ser destacados neste momento é que os dois maiores índices de migração para Porto Velho foram do estado do Amazonas, seguido pelo estado do Acre tanto em números de migrantes que se deslocaram como no total, levando-se em consideração todo o estado. De todos os amazonenses que migraram para Rondônia $85 \%$ se deslocaram para Porto Velho e $84,88 \%$ dos acreanos que se deslocaram para o estado, se estabeleceram em Porto Velho. Estes dados se estendem para o Estado do Pará onde do total do estado, $77 \%$ dos migrantes se localizaram em Porto Velho, seguido pelos maranhenses com 78\% (IBGE, 1990).

Estes dados demonstram que as migrações que compõem neste momento a cidade de Porto Velho se distinguem do Estado de Rondônia em relação à origem dos migrantes. Rondônia vivia desde a década de 1980 uma mudança na origem dos migrantes que até a década de 1970 compreendia, sobretudo, nordestinos e, a partir de 1980, os migrantes passaram a vir principalmente do estado do Paraná, Espírito Santo e Minas Gerais. Porto Velho constitui uma especificidade, pois comportou principalmente migrantes da região norte.

Todas estas informações contribuem para destacar a especificidade do processo de urbanização de Porto Velho, não somente nesta década, mas também ao longo de toda sua trajetória, a qual está inserida dentro do contexto do estado de Rondônia, sofrendo e participando das políticas implantadas, mas comportando-se 
diferentemente dos demais municípios, na maioria das vezes, em função do seu status de capital.

A população do município de Porto Velho no ano 2000, segundo os dados do IBGE, era de 336.661 pessoas, em que 315.653 pessoas, ou seja, 94,32\% localizavam-se na cidade de Porto Velho, onde os homens correspondem 156.478 e as mulheres totalizam 159.175. Este total de pessoas que moram na capital Porto Velho corresponde a $22,87 \%$ das pessoas que residem no estado de Rondônia.

A população urbana de Porto Velho era de 262.157 pessoas, que correspondia a $83,05 \%$ da população total, sendo 128.580 homens, ou seja, $19,09 \%$ e 133.577 mulheres, ou seja, 50,91\%. A população rural de Porto Velho era de 53.496 pessoas e correspondia a $16,95 \%$ da população, dos quais 27.898 eram homens, ou seja, 52,15\% e 25.598 mulheres, ou seja, 47,85\%.

Estes dados revelam aspectos importantes sobre a realidade da cidade de Porto Velho, que apresentava um predomínio da população nas áreas urbanas revelando mais uma vez o caráter urbano da cidade, além do predomínio, mesmo que pequeno, das mulheres sobre os homens na cidade, fato que pode ser explicado pela grande quantidade de óbitos durante a década de 1980/1990, no período áureo da exploração do ouro, em que muitos chefes de família perderam suas vidas na expectativa de enriquecerem garimpando no rio Madeira.

Do total da população residente de Porto Velho em 2000, 313.570 (99,34 \%) possuem domicílios particulares e permanentes, 302.000 domicílios (96,31\%) são casas, 4.745 (1,51\%) são apartamentos, 6.825 (2,17\%) são cômodos, 254 (0,08\%) são residências improvisadas e 1.092 (0,34\%) domicílios coletivos (IBGE, 2000).

Os dados do IBGE demonstram a característica horizontal das construções da cidade, onde se iniciava um processo incipiente de verticalização. Não podemos esquecer de que grande parte destas terras ocupadas por estas construções pertenciam ainda a União como herança da época em que Rondônia foi território federal. Foi concedido ao Instituto Brasileiro de Colonização e Reforma Agrária (INCRA) a posse de 93\% das terras do estado de Rondônia, sendo assim grande parte dos terrenos da cidade de Porto Velho não apresentam escritura pública, os moradores apenas possuem a posse da terra.

As condições das habitações na cidade de Porto Velho deixam muito a desejar para uma capital de estado, pois, apesar de apresentar números acima da 
média em relação aos demais municípios do estado, são insuficientes e demonstram uma realidade muito precária.

Do total de 79.353 domicílios particulares permanentes na cidade de Porto Velho, segundo o censo de 2000, 67.904 domicílios, ou seja, 85,57\% apresentam alguma forma de coleta de lixo. Destes 66.270 , ou seja, 83,51 têm suas coletas realizadas por serviço de limpeza, 1.634, ou seja, 2,05\% têm seu lixo recolhido em caçambas de serviços de limpeza, 7626, ou seja, 9,61\% queimam seu lixo, 296, ou 0,37\% queimam seus resíduos sólidos, 2303, ou 2,90\% jogam em terrenos baldios ou logradouro, 530 , ou $0,66 \%$ jogam no rio e 694 , ou $0,87 \%$ dão outros destinos para o lixo.

Os números demonstram certa uniformização quanto à coleta de lixo, pois grande parte da cidade já se beneficia desses serviços, porém a realidade tem demonstrado inconsistências quanto a estes números, encontra-se uma grande quantidade de resíduos sólidos nas ruas, parques, praças públicas e à beira do rio Madeira, fato que pode estar associado à cultura do povo e à falta de educação ambiental.

Dois fatores, o abastecimento de água e a coleta de esgoto, apresentam-se insuficientes em Porto Velho, não abrangendo todas as regiões e acontecendo de forma precária.

O censo 2000 demonstra que do total de 79.353 domicílios particulares permanentes existentes na cidade de Porto Velho, 76.182, ou seja, $96 \%$ apresentam banheiro ou sanitário e 3.171 ou 4\% não apresentam banheiro ou sanitário.

Do total de $96 \%$ dos que apresentam banheiro ou sanitário, 7.436 , ou seja, $9,76 \%$ apresentam escoamento sanitário em rede geral de esgoto ou pluvial. 43.732, ou seja, $57,40 \%$ possuem fossa séptica, 20.826 , ou $27,33 \%$ fossa rudimentar, 2.698 ou $3,54 \%$ jogam seu esgoto em valas, 892 , ou $1,17 \%$ despejam no rio e 598 , ou $0,78 \%$ utilizam outra forma de escoadouro.

Quanto ao abastecimento de água, os números não se apresentam melhores: do total de 79.353 domicílios particulares permanentes, 28.890 , ou seja, $36,4 \%$ têm acesso à rede geral de abastecimento de água. Destes 25.578 , ou $88,53 \%$ recebem a água da rede geral em pelo menos um cômodo, 3.312, ou 11,46\% possuem água canalizada na propriedade ou no terreno. 
As residências que tem seu abastecimento por poços ou nascentes totalizam 47.251, ou seja, 59,54\% do total de domicílios permanentes, onde 32.028, ou $67,78 \%$ tem a água do poço ou nascente canalizada em pelo menos um cômodo, 3.763, ou $7,96 \%$ tem água canalizada somente na propriedade, ficando 11.460 residências, ou seja, 14,44\% sem água canalizada.

Estes dados do censo do ano de 2000 do IBGE apresentam uma realidade ainda pouco desenvolvida, principalmente, em se tratando de serviços básicos de tratamento de esgoto e água potável.

Os números pouco se modificaram até o ano de 2008, porém mais uma vez a região de Porto Velho, apresenta-se dentro do contexto nacional como uma das alternativas para a resolução de problemas que se configuram em nível de Brasil.

Em virtude do grande potencial hídrico dos rios da Amazônia e de sua pouca exploração, o Rio Madeira foi o escolhido para comportar a construção de duas hidrelétricas: a de Santo Antônio e a de Jirau, que deverão garantir a produção de energia para o Brasil, contribuindo para sanar a escassez de energia elétrica do país, manifestada nos chamados apagões.

Dentro destas políticas, inclui-se o PAC (Programa de Aceleração do Crescimento do Governo Federal) lançado em janeiro de 2007, que incorporou uma gama de ações até o ano de 2010 apresentando para o estado de Rondônia previsões de investimento até o ano de 2016, conforme quadro 6.

Os recursos do PAC para o município de Porto Velho ocorreram com mais intensidade nos investimentos em infra-estrutura conforme quadro 5, ponto em que se encontram seus maiores problemas, fruto direto de todo o seu processo de urbanização e formação.

Quadro 5 - Recursos do PAC dirigidos ao município de Porto Velho no ano de 2008

\begin{tabular}{|l|c|}
\hline \multicolumn{1}{|c|}{ PROGRAMA } & VALOR EM REAL \$ \\
\hline SANEAMENTO E URBANIZAÇÃO & 105.300 .00 \\
\hline PAC/FUNASA & 14.000 .00 \\
\hline $\begin{array}{c}\text { CONSTRUÇÃO DE HABITAÇÃO DE } \\
\text { INTERESSE SOCIAL (FNHIS) }\end{array}$ & 24.500 .00 \\
\hline \multicolumn{1}{|c|}{ Total } & 143.800 .00 \\
\hline
\end{tabular}

Fonte: Plano Diretor de Porto Velho - 2008. 
Quadro 6 - Estimativa de repasse do PAC até o ano de 2016

\begin{tabular}{|c|c|}
\hline ANOS & RECEITA ESTIMADA (MILHÕES) \\
\hline 2006 & 287,5 \\
\hline 2007 & 312,8 \\
\hline 2008 & 341,2 \\
\hline 2009 & 370,4 \\
\hline 2010 & 402,4 \\
\hline 2011 & 432,9 \\
\hline 2012 & 461,7 \\
\hline 2013 & 490,0 \\
\hline 2014 & 519,3 \\
\hline 2015 & 548,2 \\
\hline 2016 & 576,9 \\
\hline
\end{tabular}

Fonte: Plano Diretor de Porto Velho, 2008.

\section{A EVOLUÇÃO DA MANCHA URBANA DE PORTO VELHO}

\subsection{IDENTIFICAÇÃO DA EXPANSÃO DA MANCHA URBANA POR MEIO DE IMAGENS DE SATÉLITE}

As imagens de satélite têm se mostrado um instrumento importante para o monitoramento da cobertura do terreno, principalmente por apresentar dados coletados desde a década de 1970. Uma das séries de imagens disponíveis com uma grande quantidade de dados passados é a da constelação Landsat, lançados pela NASA (National Aeronautics and Space Administration) e que atualmente tem seus dados distribuídos pelo INPE (Instituto Nacional de Pesquisas Espaciais).

Para analisar a expansão da mancha urbana e seu comportamento nas últimas três décadas, utilizaram-se as imagens dos satélites da série Landsat. $\mathrm{O}$ primeiro satélite da série foi o Landsat 1, lançado em 23 de julho de 1972, permanecendo em operação até 01 de junho de 1978. Abaixo, segue um quadro com os satélites desta série. 
Quadro 7 - Satélites do Programa Landsat

\begin{tabular}{|c|c|c|}
\hline SISTEMA & OPERAÇÃO & RESOLUÇÃO \\
\hline 1 LANDSAT & $23 / 07 / 1972$ a 01/06/1978 & 80 METROS \\
\hline 2 LANDSAT & $22 / 01 / 1975$ a $25 / 02 / 1982$ & 80 METROS \\
\hline 3 LANDSAT & $05 / 05 / 1978$ a 31/03/1983 & 80 METROS \\
\hline 4 LANDSAT & $16 / 07 / 1982$ a 01/08/1993 & 80 METROS \\
\hline 5 LANDSAT & $01 / 03 / 1984$ até hoje & 30 METROS \\
\hline 6 LANDSAT & $10 / 05 / 1993$ a $10 / 05 / 1993$ & 30 METROS \\
\hline 7 LANDSAT & $04 / 04 / 1999$ a 2007 & 15 e 30 METROS \\
\hline
\end{tabular}

Fonte: Adaptado de NOVO, 2008.

A imagem mais antiga disponível para a cidade de Porto Velho foi adquirida, livre de cobertura de nuvens, em 17 de maio de 1976 pelo Landsat 1. Esta imagem, como as demais utilizadas para esta análise, estão disponíveis no sítio eletrônico do Instituto Nacional de Pesquisas Espaciais (INPE) (http://www.dgi.inpe.br/CDSR).

As imagens utilizadas para analisar a evolução e o comportamento da mancha urbana da cidade de Porto Velho compreendem um período de 1976 e 2010, tendo suas respectivas datas de aquisição apresentadas na tabela VII.

Para que a análise pudesse considerar os aumentos de área, as imagens foram registradas utilizando como base a imagem do ano de 2008 resultando num conjunto devidamente registrado e georreferenciado.

As análises e quantificações do aumento da mancha urbana foram realizadas em Sistema de Informações Geográficas (SIG) utilizando, para a interpretação da área urbana, uma chave de interpretação considerando a cor, textura, forma e rugosidade (NOVO, 2008) apresentadas na imagem. Dessa forma, com o conjunto de imagens devidamente registradas, foi possível identificar a mudanças de padrão na imagem comparando visualmente com os anos anteriores, permitindo assim, a identificação de alterações na cobertura da terra em decorrência da expansão urbana por meio da construção de seus equipamentos como estradas, casas ou loteamentos.

Neste caso, justifica-se a interpretação visual por conta do crescimento da cidade estar caracterizada, principalmente, por construções de pequeno número de pavimentos, ou seja, pouco ou quase nada verticalizadas. A cidade de Porto Velho é caracterizada por ser uma cidade horizontalmente distribuída, apresentando poucos 
prédios como mostram as fotografias aéreas tomadas em 27 de maio de 2008 (figura 3 e 4)

Figuras 3 e 4 - Apresentam a horizontalidade da cidade
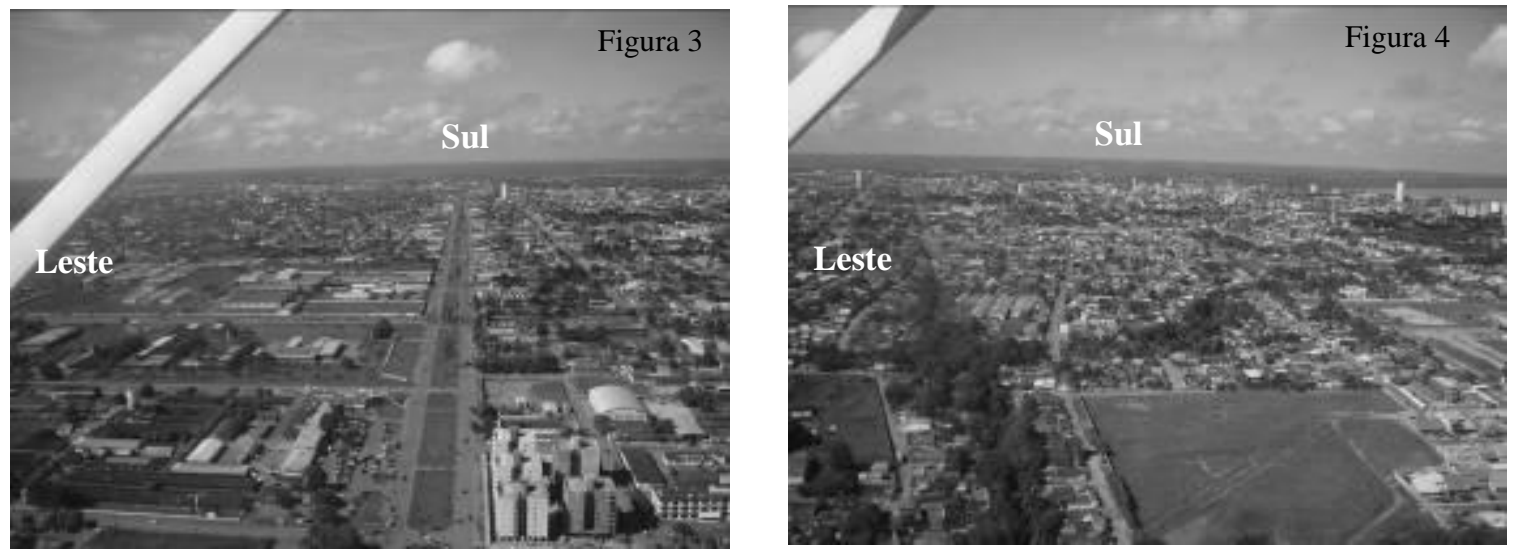

Foto: Maurício Silva, 27/05/2008.

Como resultado dessa interpretação, foram criados diversos vetores que representam os acréscimos de área urbana horizontal, com seus respectivos anos de interpretação referentes às imagens. A partir desse conjunto de vetores, foi possível calcular as áreas de acréscimo de área urbana horizontal para cada ano na cidade de Porto Velho como mostra o mapa 1.

Em função de grande presença de nuvens nas imagens obtidas na região Amazônica, o que impede a visualização do terreno, o conjunto de imagens disponíveis para interpretação não apresenta uma distribuição linear ao longo do tempo, havendo assim a necessidade de extrapolar as análises e as formas de apresentação dos resultados da evolução. Para tanto, foi calculado o quantitativo do período e dividido igualmente pelo número de anos para estabelecer a taxa anual de acréscimo de área urbana.

Vale ressaltar que este valor mostra a tendência de crescimento horizontal, e que o valor de acréscimo real somente pode ser considerado real no período, que em algumas análises chega a 4 anos e em outros a 1 ano, mas, o mais comumente ocorrido foi um lapso temporal para nova imagem de 2 anos. Desta forma, foi possível melhor apresentar os acréscimos e estabelecer um parâmetro anual de expansão da mancha urbana de Porto Velho. 
Mapa 1 - Evolução da mancha urbana de Porto Velho

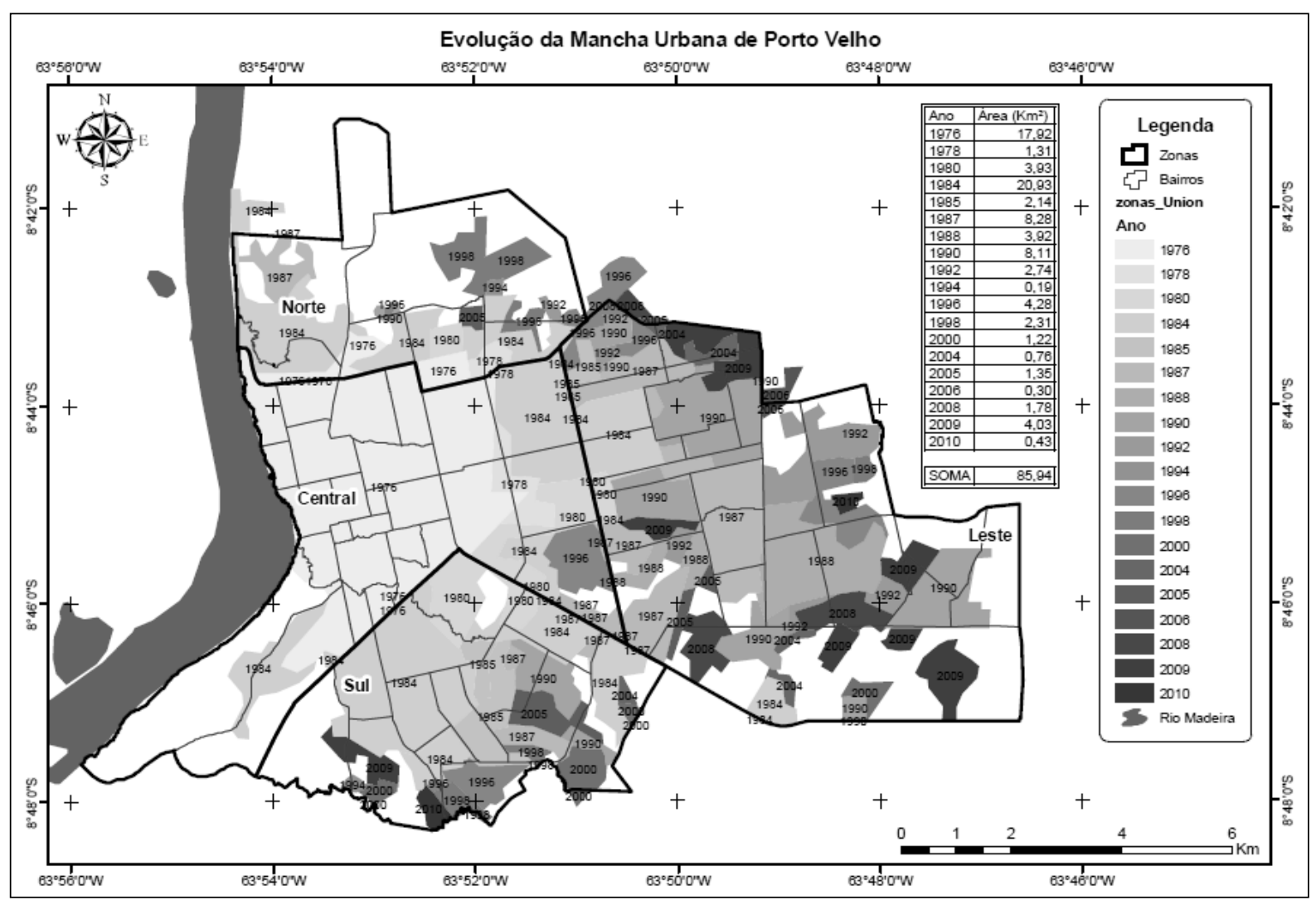

Fonte: Dissertação de mestrado - Claúdia Pinheiro Nascimento, 2009.

\subsection{DADOS DA EVOLUÇÃO DA MANCHA URBANA DE PORTO VELHO}

Os resultados oriundos da interpretação para o período observado e a taxa anualizada estão apresentadas no quadro 8. 
Quadro 8 - Avanço da mancha urbana 1976-2010

\begin{tabular}{|c|c|c|c|c|}
\hline $\begin{array}{c}\text { DATA } \\
\text { IMAGEM } \\
17 / 06 / 1976\end{array}$ & $\begin{array}{l}\text { ANO } \\
1976\end{array}$ & $\begin{array}{c}\begin{array}{c}\text { AVANÇO } \\
\text { Km²/PERIODO }\end{array} \\
\text { Km }^{2} 17,92\end{array}$ & ANO & $\begin{array}{l}\text { AVANÇO } \\
\mathrm{Km}^{2} / \text { ANO }\end{array}$ \\
\hline \multirow{2}{*}{ 30/06/1978 } & \multirow{2}{*}{1978} & \multirow{2}{*}{1,31} & 1977 & 0,64 \\
\hline & & & 1978 & 0,64 \\
\hline \multirow{2}{*}{ 08/09/1980 } & \multirow{2}{*}{1980} & \multirow{2}{*}{3,93} & 1979 & 1,80 \\
\hline & & & 1980 & 1,80 \\
\hline \multirow{4}{*}{ 24/06/1984 } & \multirow{4}{*}{1984} & \multirow{4}{*}{20,93} & 1981 & 5,52 \\
\hline & & & 1982 & 5,52 \\
\hline & & & 1983 & 5,52 \\
\hline & & & 1984 & 5,52 \\
\hline $13 / 07 / 1985$ & 1985 & 2,14 & 1985 & 2,03 \\
\hline \multirow{2}{*}{ 03/07/1987 } & \multirow{2}{*}{1987} & \multirow{2}{*}{8,28} & 1986 & 4,20 \\
\hline & & & 1987 & 4,20 \\
\hline 05/07/1988 & 1988 & 3,92 & 1988 & 3,90 \\
\hline \multirow{2}{*}{ 12/08/1990 } & \multirow{2}{*}{1990} & \multirow{2}{*}{8,11} & 1989 & 3,86 \\
\hline & & & 1990 & 3,86 \\
\hline \multirow{2}{*}{ 01/08/1992 } & \multirow{2}{*}{1992} & \multirow{2}{*}{2,74} & 1991 & 1,39 \\
\hline & & & 1992 & 1,39 \\
\hline \multirow{2}{*}{ 04/06/1994 } & \multirow{2}{*}{1994} & \multirow{2}{*}{0,19} & 1993 & 0,10 \\
\hline & & & 1994 & 0,10 \\
\hline \multirow{2}{*}{ 25/06/1996 } & \multirow{2}{*}{1996} & \multirow{2}{*}{4,28} & 1995 & 2,08 \\
\hline & & & 1996 & 2,08 \\
\hline \multirow{2}{*}{$17 / 07 / 1998$} & \multirow{2}{*}{1998} & \multirow{2}{*}{2,31} & 1997 & 1,12 \\
\hline & & & 1998 & 1,12 \\
\hline 06/07/2000 & 2000 & 122 & 1999 & 0,62 \\
\hline $0 b / 0 / / 2000$ & 2000 & 1,22 & 2000 & 0,62 \\
\hline & & & 2001 & 0,18 \\
\hline & & & 2002 & 0,18 \\
\hline $06 / 17 / 2004$ & 2004 & 0,16 & 2003 & 0,18 \\
\hline & & & 2004 & 0,18 \\
\hline $04 / 07 / 2005$ & 2005 & 1,35 & 2005 & 2,05 \\
\hline 08/08/2006 & 2006 & 0,30 & 2006 & 0,28 \\
\hline 28/07/2008 & 2008 & 178 & 2007 & 0,90 \\
\hline & & 1,18 & 2008 & 0,90 \\
\hline $15 / 07 / 2009$ & 2009 & 4,03 & 2009 & 4,18 \\
\hline $15 / 05 / 2010$ & 2010 & 0,43 & 2010 & 0,51 \\
\hline
\end{tabular}

Fonte: Dissertação de mestrado - Claúdia Pinheiro Nascimento, 2009.

Pode-se observar que, no início do levantamento (1976), Porto Velho apresentava uma área urbana de $17,92 \mathrm{Km}^{2}$ e que o maior avanço da mancha urbana ocorreu no período de 1980 a 1984, apresentando um crescimento de 20,93 $\mathrm{Km}^{2}$ para o período. Em função da ausência de imagens descobertas de nuvens, este foi o maior lapso temporal de análise, assim, não foi possível identificar se o 
crescimento foi bem distribuído ao longo destes anos ou concentrado num único ano.

Os primeiros anos de análise foram os que apresentaram o maior crescimento, período compreendido entre os anos de 1980 e 1990 que apresentam juntos $50 \%$ de todo o crescimento interpretado $\left(43,38 \mathrm{Km}^{2}\right)$. Considerando o exposto, a década de 1980 foi a que apresentou o maior avanço da mancha urbana, principalmente entre os anos de 1980 a 1984 e nos anos de 1986-1987. Dos 85,94 $\mathrm{Km}^{2}$ de área urbana que a cidade apresenta em 2010, $34 \%\left(29,22 \mathrm{Km}^{2}\right)$ ocorreram neste período.

As duas décadas seguintes, de 1990 e 2000, apresentaram crescimentos menores, $21 \%$ e $15 \%$ respectivamente, apresentando avanços de 13,87 e 9,64 $\mathrm{Km}^{2}$, como mostra o gráfico IV. Durante a década de 1990, o período 1988-1990 apresentou o maior avanço acumulado, $8,11 \mathrm{Km}^{2}$, mas deve-se considerar que, neste período, está compreendido o ano de 1989 ainda da década anterior. No período de 1994-1996 foi identificado outro grande avanço nesta década com 4,28 $\mathrm{Km}^{2}$ interpretados.

A década de 2000 (2000-2009) registrou seu maior avanço no ano de 2009, com 4,03 $\mathrm{Km}^{2}$ de avanço da mancha urbana, evolução esta registrada entre 28/07/2008 e 15/07/2009, conforme as imagens disponíveis, segundo gráfico 3 e 4.

Gráfico 3 - Avanço da mancha urbana de Porto Velho de 1976 a 2010

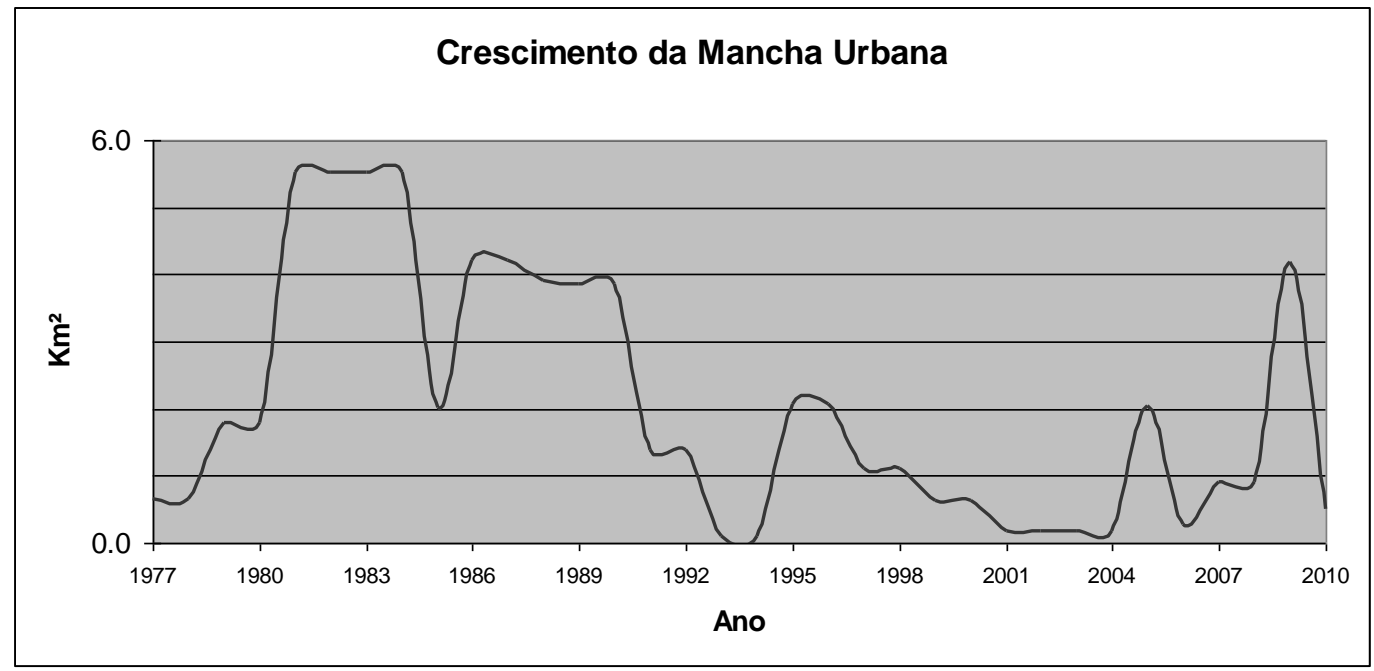

Fonte: Dissertação de mestrado - Claúdia Pinheiro Nascimento, 2009. 
Gráfico 4 - Crescimento acumulado por década

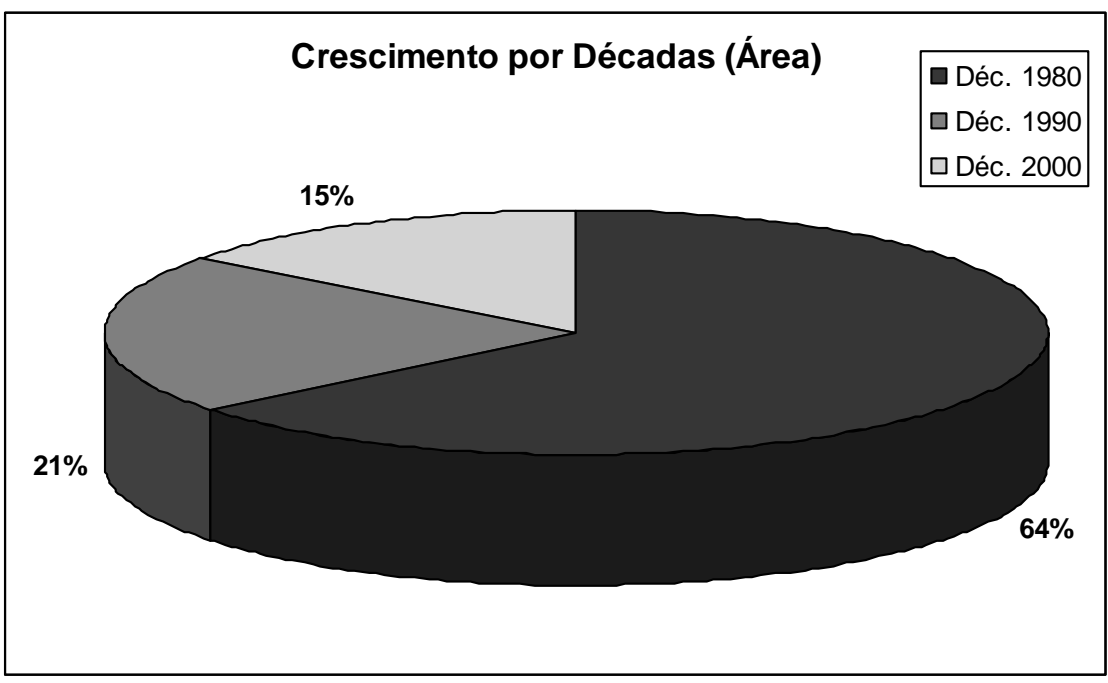

Fonte: Dissertação de mestrado - Claúdia Pinheiro Nascimento, 2009.

\section{PANORAMA DA VERTICALIZAÇÃO ATUAL DE PORTO VELHO}

Face ao atrativo das obras das hidrelétricas de Santo Antônio e Jirau, uma nova leva migratória inundou Porto Velho: algo em torno de cem mil pessoas. A maioria são trabalhadores com pouca ou nenhuma qualificação. Mas um contingente significativo desse montante migratório é de profissionais liberais e técnicos qualificados. Para acomodar esse pessoal um boom imobiliário toma conta da cidade.

Porto Velho reedita a onda imobiliária da década de oitenta quando da instalação do estado local. Dessa vez, a verticalização acontece de modo difuso em torno da área central da cidade, e não mais concentrada no bairro das Pedrinhas como nos anos oitenta.

$\mathrm{Na}$ foto abaixo, vê-se a construção do novo centro administrativo do estado de Rondônia, que irá substituir os antigos blocos de pavimento único que formavam a Esplanada das Secretarias. Esse local foi o epicentro do processo imobiliário da década de oitenta, pois, em torno dele surgiu o bairro das Pedrinhas para acomodar os integrantes do quadro oficial, conforme figura 5. 
Figura 5 - Centro Administrativo do Governo do Estado de Rondônia, em Porto Velho

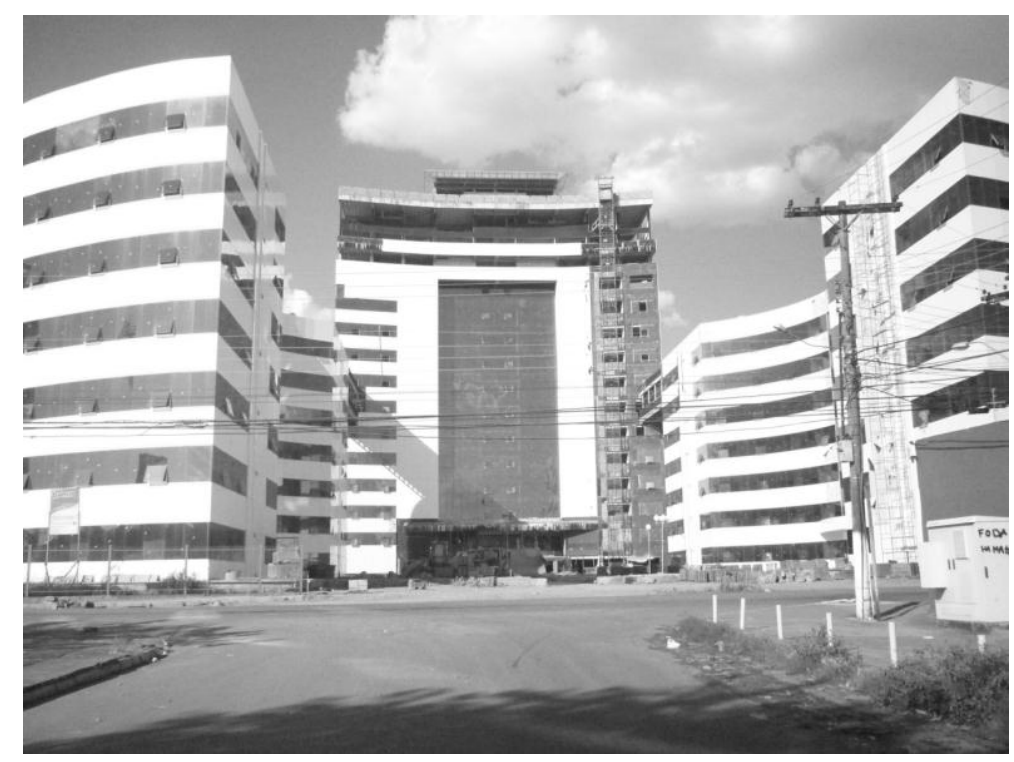

Fonte: Foto de Tales José Cosentino Santos, 30/06/2011.

As fotos abaixo (figura 6 e 7) mostram a dispersão da atual verticalização em torno do núcleo urbano de Porto Velho.

Figura 6 e 7 - Verticalização em torno do núcleo urbano da cidade de Porto Velho
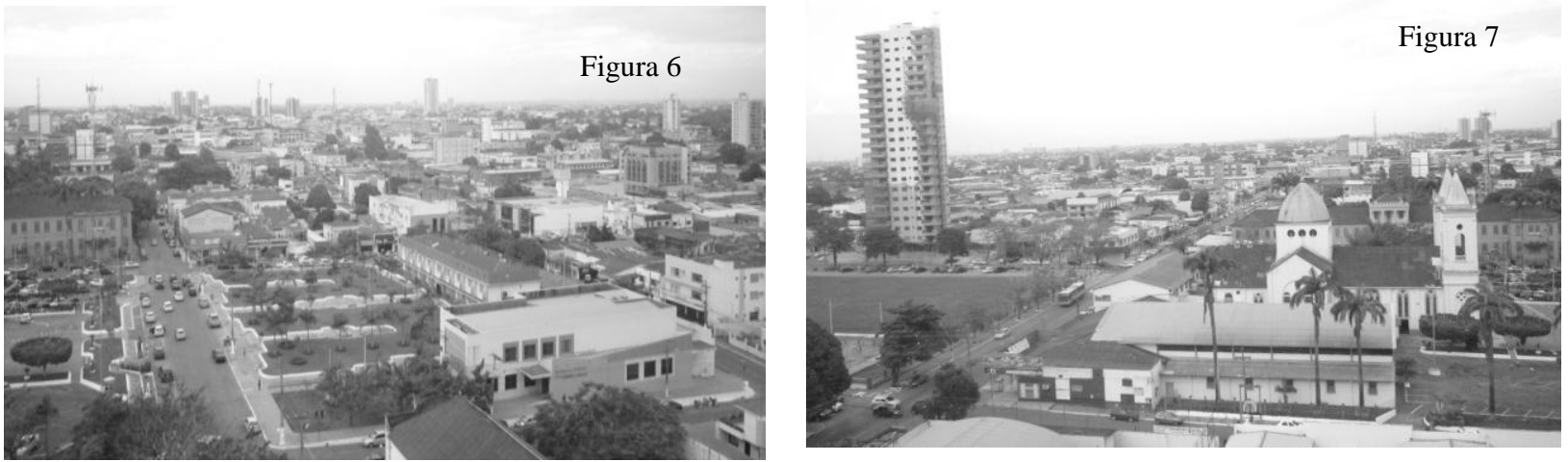

Fonte: Foto de Tales José Cosentino Santos, 30/06/2011. 
$\mathrm{Na}$ foto a direita acima (figura 8), as torres e a cúpula da catedral de Porto Velho contrastam com o imponente edifício à esquerda, mostrando a convivência arquitetônica do antigo e do moderno.

Figura 8 - Edificações na região norte da cidade que marcam a revitalização do entorno da esplanada das secretarias.

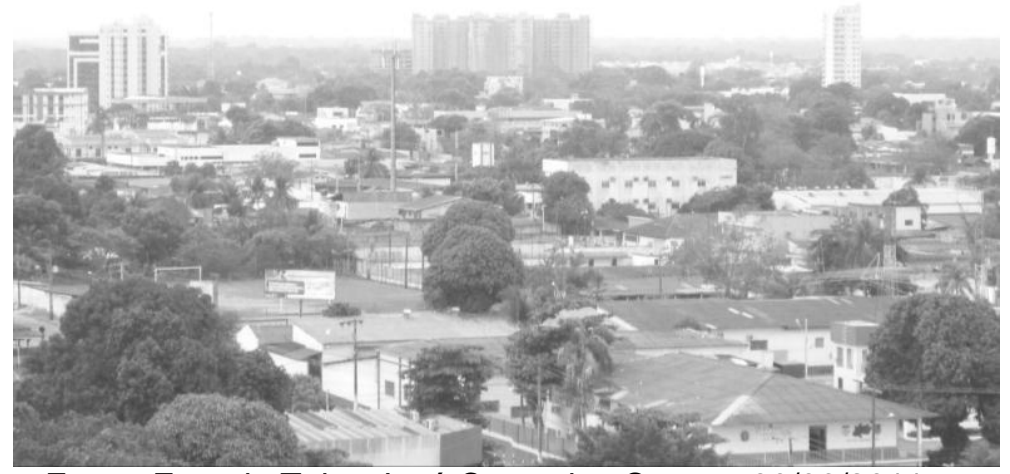

Fonte: Foto de Tales José Cosentino Santos, 30/06/2011.

$\mathrm{Na}$ foto acima (figura 8), um instantâneo das recentes edificações ao norte da cidade que marcam a revitalização urbana do entorno da antiga Esplanada das Secretarias.

Enfim, para finalizar, um close da área onde a cidade nasceu e como se mostra hoje. No fundo, o rio Madeira, os galpões da Madeira-Mamoré, e o novo mercado municipal, além do prédio do antigo hotel no plano médio, hoje sede da Unir, e, em primeiro plano, o palácio do governo estadual, conforme figura 9.

Figura 9 - Vista da cidade de Porto Velho. Ao fundo o rio Madeira.

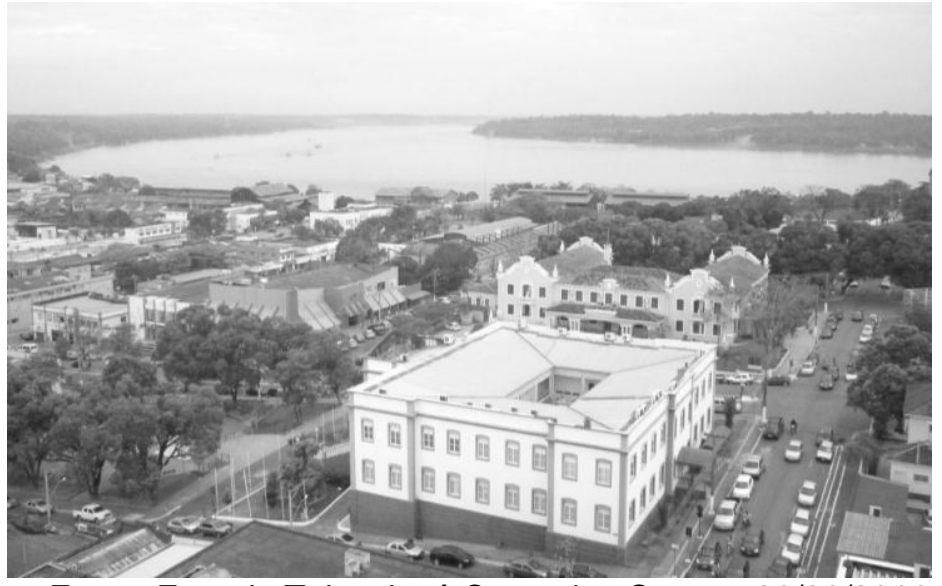

Fonte: Foto de Tales José Cosentino Santos, 30/06/2011. 


\section{CONCLUSÃO}

O processo de formação sócio-espacial de Porto Velho esteve, ao longo de sua história, associado às políticas implantadas para a incorporação e ocupação do estado assim como os ciclos econômicos que se estabeleciam na região em busca dos seus recursos naturais.

A condição de Porto Velho, como capital político administrativa, foi o grande indutora da urbanização que se difundiu para o restante do estado de Rondônia.

Este processo intensificou-se na década de 1980, quando Rondônia passa da categoria de Território para Estado, e Porto Velho, além de comportar todo o aparato institucional do Estado, destaca-se pela instalação de serviços especializados e pela mobilização de recursos humanos, o que acarretou um aumento do poder aquisitivo e a ampliação do mercado consumidor local e regional.

Todos estes fatores contribuíram para que Porto Velho assumisse a condição de centro regional frente aos demais municípios que surgiam no Estado de Rondônia na década de 1980, assim como foram elementos importantes na constituição do espaço de Porto Velho, no crescimento da população, assim como a expansão da sua mancha urbana.

O crescimento da mancha urbana e o crescimento da população na cidade de Porto Velho estão diretamente relacionados, apresentando os maiores crescimentos da mancha urbana nos períodos de maior crescimento populacional, reforçando o caráter de espalhamento da cidade.

Da mesma forma que o crescimento urbano tem sua relação direta com o crescimento da população, de igual modo, ambos promovem uma maior dinamização da economia e da política local. Assim, o maior crescimento da mancha urbana registrado na década de 1980 apresenta-se diretamente relacionado ao fluxo migratório oriundo dos contingentes não absorvidos pelos projetos de colonização e do efêmero ciclo da atividade aurífera no Madeira.

Na década de 1990, muitas foram as ações que estimularam o crescimento da população. Difícil apontar um principal fator indutor do avanço da mancha urbana, porém os primeiros resultados de estabilidade econômica oriundos do Plano Real refletiram na dinâmica urbana registrada (1994-1996) para esta década. Essa é a década de vigência do primeiro Plano Diretor de Porto Velho. 
$\mathrm{Na}$ década de 2000, o crescimento da mancha urbana teve dois momentos importantes. O primeiro entre 2004-2005, reflexo do anúncio do complexo de Usinas do rio Madeira. O outro em 2009, reflexo da efetiva implantação dos empreendimentos impulsionados pelo PAC, que trouxe uma nova característica à cidade, a verticalização, associada a um boom imobiliário que movimenta a economia da cidade.

Porém, todos estes processos que estiveram associados a ciclos econômicos ou à implantação de planos governamentais, na maioria das vezes, não contribuíram para o desenvolvimento das condições mínimas de urbanização da cidade, que apresentava os piores índices de saneamento básico, água tratada até o ano de 2008, quando iniciaram as obras do PAC, tendo seus maiores investimentos na parte de urbanização, saneamento e habitação precária.

\section{REFERÊNCIAS}

BECKER, B.; MIRANDA, M.; MACHADO, L. O. (Orgs.). Fronteira Amazônica: Questões atuais sobre a gestão do território. 1. ed. Brasília: Editora da Universidade de Brasília e Editora da UFRJ, 1990. 219 p.

COY, M. Relações entre campo e cidade em áreas de colonização governamental e particular. Os exemplos de Rondônia e do Norte Matogrossense. In: I Congresso de Americanitas. Amsterdam, p. 1-14, 1988.

IBGE - Instituto Brasileiro de Geografia e Estatística. Censo Populacional. Rio de Janeiro. 1980

—. Contagem Populacional. Rio de Janeiro, 1990

. Contagem Populacional. Rio de Janeiro, 1995

. Contagem Populacional. Rio de Janeiro, 1996.

. Contagem Populacional. Rio de Janeiro, 2000.

. Contagem Populacional. Rio de Janeiro, 2010.

FIBGE - Fundação Instituto Brasileiro de Geografia e Estatística. A Organização do Espaço na Faixa da Transamazônica. Rio de Janeiro: FIBGE, vol. 50, 1979.

Estimativa de Censo. Rio de Janeiro: FIBGE, 1992.

Censo 2000. Rio de Janeiro: FIBGE, 2000. 
FIERO - Federação das Indústrias de Rondônia. Rondônia: Perfil e Diretrizes de Desenvolvimento Industrial e de Infraestrutura. Porto Velho: FIERO, 1995.

\section{Perfil Sócio-Econômico e Industrial. Porto Velho: FIERO, 1997.}

\section{Cadastro de Empresas. Porto Velho: 1997.}

HENRIQUES, M. H. F. da T.. A dinâmica demográfica de uma área de fronteira: Rondônia. Revista Brasileira de Geografia, Rio de Janeiro, v.46, n.03/04, p. 317 356, 1985.

Os colonos de Rondônia: Conquistas e Frustrações. Revista Brasileira de Geografia, Rio de Janeiro, v.48, n. 01, p. 03 - 42, 1986.

MACHADO, L. O. Urbanização e políticas de integração no norte de Goiás. 1979. Dissertação (mestrado) - Universidade Federal do Rio de janeiro, UFRJ, Rio de Janeiro - RJ.

MIRANDA, M. \& MACHADO, L. O. Fronteira Amazônica: Questões sobre a Gestão do Território. Rio de Janeiro/Brasília: UFRJ/UnB, p. 115-130, 1990.

MAHAR, D. J. 1983. "Development of the Brazilian Amazon: Prospects for the 1980s" in: The Dilemna of Amazonian Development. E. F. Moran , ed., Boulder, CO: Westview Press.

MILLIKAN, B. H., Zoneamento Sócio-Econômico-Ecológico e Políticas Públicas no Estado de Rondônia: Oportunidades, Limites e Desafios para o Desenvolvimento Sustentável. Governo de Rondônia, SEPLAN, PNUD/PLANAFLORO, Porto Velho, janeiro 1998.

NASCIMENTO, C. P. Cenários da Produção Espacial Urbana de Porto Velho. 2009. Dissertação (mestrado) - Programa de Pós Graduação Mestrado em Geografia, UNIR, Porto Velho - RO.

NOVO, E. M. L. de M. Sensoriamento Remoto: princípios e aplicações. São Paulo: Editora Blucher, 2008.

PUMAIN, D. An impicit large territorial-technical system: settlement systems. Paris: FLUX, n. 21, July-September, p. 11-20, 1995.

$$
\text { Pour une théorie évolutive des villes. Paris: L'Espace }
$$

Geographique, n. 2, p. 120-134, 1997.

SANTOS, C. A Fronteira do Guaporé. Porto Velho: Edufro, 2001.

SEDAM - Secretaria Estadual do Meio Ambiente. Mapas Fitogeográficos de Rondônia. Porto Velho. 1989.

TEIXEIRA, M. A. D; FONSECA, D. R. História Regional: Rondônia. Porto Velho: Rondoniana, 2002, $232 \mathrm{p}$. 
Revista Geografar

Curitiba, v.7, n.1, p. 20-52, jun./2012

\section{SITES PESQUISADOS}

http://pesquisa.rondonia.ro.gov.br/index3.html

http://www.ibge.gov.br

$\underline{\text { http://www.dgi.inpe.br/CDSR }}$

(Recebido em 01.08.2011. Aceito em 13.02.2012) 